\title{
Do Hedonic or Utilitarian Types of Online Product Reviews Make Reviews More Helpful?
}

\section{A New Approach to Understanding Customer Review Helpfulness on Amazon}

\author{
Maidul Islam, Keimyung University, South Korea \\ Mincheol Kang, Ajou University, South Korea \\ Tegegne Tesfaye Haile, The University of Suwon, South Korea \\ (iD) https://orcid.org/0000-0003-3968-6102
}

\begin{abstract}
Online sales can be influenced significantly by customer reviews; thus, there are several studies on what makes an online review helpful to consumers. However, none of those researches address the review helpfulness in the context of hedonic and utilitarian review types. This study examines how product type (hedonic and utilitarian) moderates the relationship between the level of review type (hedonicity and utilitarianity) and review helpfulness. To test the moderating effects, customer review data for perfume and bar soap product was collected from Amazon.com and analyzed by using a text-mining tool (QDA Miner) and a structural equation modeling software (AMOS 22.0). The results of this study indicate that the product type moderates the impact of the review type on review helpfulness when product type and review type are incongruent. Further, results show that the number of sentences in a customer review affects the review helpfulness when product type is utilitarian.
\end{abstract}

\section{KEYWORDS}

Amazon, Customer Review, Hedonic, Product Type, QDA Miner, Review Helpfulness, Review Type, Utilitarian

\section{INTRODUCTION}

Consumer opinions or experience on products that are shared with other prospective buyers in the form of customer reviews on e-commerce sites is used as a source of information that consumers access instantly and regularly (Wang et al., 2018). Customer reviews play a significant role in making an online purchasing decision (Wang et al., 2018). The consumer-generated review serves two functionalities (Park et al., 2007). The first one is to help e-shoppers to evaluate products and services before making a purchasing decision (Wan \& Nakayama, 2014). The second is it helps the consumers to get familiar with the products or services before they make the purchase. Consumers can accumulate information about the product even though they don't have the intention of buying it right away (Chen \& Xie, 2008). 
Researchers have found that firms' sales can be influenced by customer reviews (Chen \& Xie, 2008; Ghose \& Ipeirotis, 2006; Guo et al., 2017). Customer reviews with post-purchase information are believed to be more helpful than company-generated information (Bickart \& Schindler, 2001). Nowadays, consumers believe other consumers' judgment more than firm-generated ads. This is because sellers tend to hide information that may harm their revenue and just highlight the good aspects on the other hand consumers provide genuine feedback on the products. Moreover, company created content are more standardized and mostly written in an objective manner, whereas consumer-created content in other word customer reviews can be subjective or objective where they can express their emotion, strength or weakness of the products (Chen \& Xie, 2004). Also, out of 10 respondents 9 of them either "completely" or "somewhat" trusted peer recommendations. Trust factors among other potential customer reviews online are higher than market-generated content (Flanagin \& Metzger, 2013). In present-day practice, most of the online retail platforms show review star rating and the number of votes, which indicated the review's helpfulness. Even though this helpfulness voting gives some understanding about the usefulness of the review, however, perceive value of every individual might be a subjective matter and may value them differently (Ham et al., 2019). An online review can be considered valuable when it has been rated by the reader as worthy and enjoying (Park \& Nicolau, 2015). Perceive value of the same product can be expressed differently as the viewpoint of each individual is different (Eisenhardt \& Zbaracki, 1992; Robey \& Taggart, 1982). Therefore, perceived value can be distinguished as hedonic review and utilitarian review. Realizing these facts, companies encourage consumers to write and share their experience towards products on their e-commerce sites as a review (Mayzlin, 2006; Cantallops \& Salvi, 2014). For example, online travel agencies like Expedia and Agoda actively look for consumers' opinions by sending a reminder email to post reviews to those who already used their service but do not post reviews. Interestingly, Amazon, one of the top e-tailers, eliminated its major spending for television and general printing advertising. Instead, the company turned to customer reviews. Amazon offers not only editorial reviews but also customer reviews or opinions from the customers who already bought that book and provided their star rating (Thompson, 2003). Several empirical studies done in the last decade stated the importance and influence of helpful reviews on commodities (Zhu \& Zhang, 2010), new products as well as services (Ye et al., 2011). Chen and Xie (2008) mentioned that helpfulness votes on review positively influence sales.

There are quite a few studies on what makes an online review helpful to consumers. Some of those studies have examined product types and review helpfulness (e.g., (Park \& Kim, 2008; Sen \& Lerman, 2007; Susan \& David, 2010). However, very few of those researches address the review helpfulness in the context of hedonic and utilitarian review types. In particular, this study evaluates customer reviews based on the review types and examines how product type (classified as hedonic and utilitarian) moderates the relationship between the level of review types (measured as hedonicity and utilitarianity) and review helpfulness. This study used Amazon's review data to test hypotheses.

In the endeavor to answer the question "which type of product reviews makes online reviews more helpful?" This study has analyzed the collected data using QDA Miner software. The following section presents the literature review, methodology, results, discussion, and conclusion of the study.

\section{LITERATURE REVIEW}

\section{Review Helpfulness}

Online reviews offer plenty of information and knowledge of products to online buyers. However, a large number of reviews for a single product can create information overload to the online buyers instead of finding a truly helpful one (Park et al., 2007; Wan et al., 2007). Therefore, e-commerce websites decided to help online buyers to screen those reviews and recognize quality reviews meritoriously. Amazon was one of the online companies that encountered such a type of problem and came up with 
a helpfulness voting which helps to filter useful and non-useful reviews based on customer voting. This Amazon review system permits online buyers not only to read or write product reviews but also permits others to vote helpfulness of the reviews. Reviews with the highest helpfulness votes are featured on the product page.

Review helpfulness can be calculated by several sets of features, e.g., sentiments type and information quality. Kim et al. (2006) suggested an algorithm to automatically accessing review helpfulness by incorporating review length and sentiment words. Zhang and Tran (2010) proposed a probabilistic distribution model, which can evaluate review helpfulness. Huang et al. (2015) argued that the review helpfulness can be determined by word count (quantitative factors). Wordiness, in general, is considered helpful as it is directly proportional to the amount of information feature for understanding its helpfulness. On the flip side, wordiness accompanies excess concept repetition; unnecessary details may lead to poor scoring on review helpfulness.

As described so far, there have been lots of studies examining which features are related to review helpfulness. However little studies, if any, have explored the effect of hedonic and utilitarian words or sentences on review helpfulness. Hedonic or utilitarian words or sentences would be key information carriers of reviews and thus they can play important roles in determining review helpfulness. The present study hires the numbers of hedonic and utilitarian sentences included in each review as predictors of review helpfulness. We believe results of this paper will significantly contribute online retailers to understand what kind of content they should put in their product description section. For instant- do they need to emphasis writing hedonic content while selling utilitarian product besides just writing utilitarian functionality in their product description section and vice-versa. The unique method of categorizing reviews into hedonic and utilitarian itself contribute to reduce the literature gap.

\section{Hedonic and Utilitarian Types of Reviews}

Customer reviews can be seen as a way of communication among existing customers who have purchased the product and prospective customers who are considering buying the product (Korfiatis et al., 2012). In marketing, communication plays an important role when it comes to hedonic and utilitarian consumption (Kronrod et al., 2012). Hedonic consumption involves affective experiences, and emotional, fantasy, sensual pleasure, and fun (Adaval, 2001; Kivetz \& Simonson, 2002; López \& Ruiz, 2011). On the other hand, utilitarian consumption is more cognitively driven, instrumental and goal-oriented and accomplishes a functional or practical task (López \& Ruiz, 2011; Strahilevitz \& Myers, 1998). Communications are mainly performed through languages. Luna et al. (2003) showed that language can influence the perceptions and attitudes of customers toward a Web site. In particular, language affects the emotions and mood of listeners (Leggitt \& Gibbs, 2000). Kronrod et al. (2012) found that assertive language is more close to hedonic characteristics and non-assertive language is perceived as more utilitarian. In a fairly recent research study, several scholars explore the importance of hedonic and utilitarian value online and found that hedonic and utilitarian review play important role in restaurant industry (Hlee et al., 2019).

The hedonicity and utilitarianity of the review might affect the review helpfulness if the reviews are classified into these two categories. If we think of two reviews with a 5-star rating that might read "I really love the product, it is amazing" whereas the other review is "this product is really useful, product features are handy to use". Both reviews are positive however the first one consists of emotional attachment or emotional sentence hence this kind of sentence is hedonistic type whereas the second one is informative therefore it may consider the utilitarian type of review. Due to the different nature of the reviews, people may find that review helpfulness differently. Heilman (1997) asserted that low arousal is characterized by relaxation such as boredom and sadness on the other hand high arousal is characterized by activation such as excitement. Excitement states can catalyze the action-related behavior of individuals and can influence their behavior (Gaertner \& Dovidio, 1977). A person writing a high emotional word, in other way hedonic words, can also be seen as an expression of a state of mind and can consider a more authentic and genuine review, which may increase the helpfulness 
of the review (Gomes et al., 2013; Kensinger \& Corkin, 2004). Informative writing often lacks the emotional wallop of a personal essay which turns out to be boring to read (Rawlins \& Metzger, 2014). Hence it is expected that review helpfulness may be affected differently by the review type.

\section{Hedonic and Utilitarian Types of Products}

Products can be categorized in different ways. For example, products can be grouped into search goods and experience goods (Nelson, 1970; Susan \& David, 2010). The present study follows Bhat and Reddy's (Bhat \& Reddy, 1998) category that classifies products as a hedonic type and utilitarian type. A product with a hedonic claim describes a notable benefit that fulfills hedonic needs for sensory pleasure and emotional identity like happiness, surprise. Similar conclusion was drawn by Bettiga et al. (2020). Li et al. (2020) have also mentioned that consumer look for fun, enjoyment and pleasure in the process of making hedonic product purchase. On the other hand, a utilitarian claim focuses a pragmatic benefit. Bhat and Reddy (1998) argue that "within most product categories, consumers' needs could be either functional or symbolic in nature, and brands could be positioned to satisfy either of these two types of needs". Freud (1955) asserts hedonic consumption includes emotional stimulation which consists of feelings like jealousy, joy, fear, and reputation. Whereas utilitarian consumption is more rational in nature (Babin et al., 1994). A similar assumption of hedonic and utilitarian consumption has been drawn by several other researchers (Adaval, 2001; Alba \& Williams, 2013; Kivetz \& Simonson, 2002). A very recent study done by Liu et al. (2020) also explained customer consumption depends on both hedonic and utilitarian components and it is important to understand the emotive and multisensory aspects of shopping behavior.

Past studies also have shown that product types can affect the effectiveness of reviews. Zhu and Zhang (2010) found that online reviews affect more sales of less popular games than sales of more popular games. Susan and David (2010) discovered the importance of in-depth product reviews and their helpfulness for search goods than for experience goods. Sen and Lerman (2007) found that product type moderates the impact of review valence, and readers of review display a negativity bias (i.e., weighting negative information more than positive information during evaluation) for utilitarian product reviews only.

Realizing the importance of studying relationships between product types and review (hedonicity and utilitarianity), this study examines in what way different combinations of product type and review type affect review helpfulness when both product type and review type are classified or measured from hedonic-utilitarian perspective. In particular, this study expects that the product type moderates the impact of the review type on review helpfulness. Interestingly, according to Mandler (1982), a congruent relationship is not very noteworthy, that is, congruent information is processed less elaborately than incongruent information, and, therefore congruent information is not as memorable as incongruent information. If we apply the Mandler (1982) schema-congruity theory to this study, we may say that a customer review would be more helpful when the product type is mismatched with the review type. For example, reviews incorporating utilitarian sentences or words could increase the review helpfulness when the product is hedonic. A similar conclusion was reached by Lim and Ang (2008). According to them, hedonic products promoted with utilitarian benefits or utilitarian products promoted with hedonic benefits are perceived as novel and favorable responses as consumers are delighted when they can make sense of the moderation incongruity. Therefore, this study proposes the following two (H1 and $\mathrm{H} 2)$ hypotheses.

Hypothesis One: Hedonic type of product significantly moderate the relationship between utilitarianity (i.e., utilitarian level) of customer review and review helpfulness.

Hypothesis Two: Utilitarian type of product significantly moderate the relationship between hedonicity (i.e., hedonic level) of customer review and review helpfulness. 


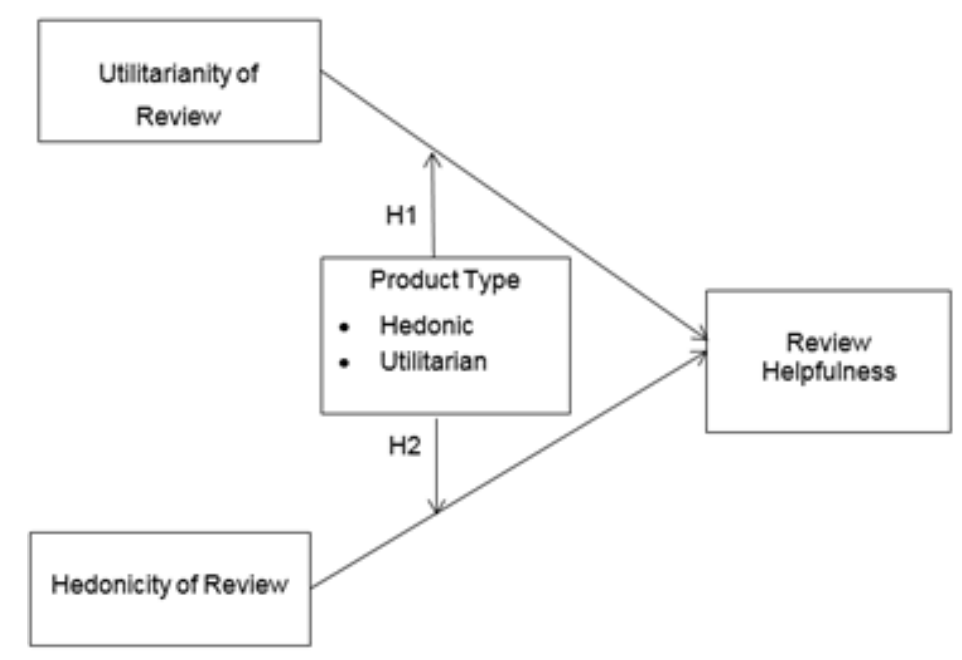

\section{METHODOLOGY}

\section{Research Model}

The research model presented in Figure 1 below demonstrates two factors that play important roles when determining the online review helpfulness. These are review types (measured as hedonicity and utilitarianity) and product type (categorized as hedonic and utilitarian). This study expects the product type to moderate the impact of the review type on review helpfulness. To test the hypotheses, this study uses actual online product reviews from one of the most popular online platforms (Amazon.com).

\section{Product Categories}

When studying foreign branding and its effects on product perceptions and attitudes experimentally, Leclerc et al. (1994) have investigated two hedonic products namely fragrance (in other words perfume) and nail polish. Lim and Ang (2008) used bar soap as a utilitarian product in their study on hedonic and utilitarian consumption. Voss et al., (2003) also considered bar soap as utilitarian products due to its highly functional properties and less hedonic functionalities. The present study chose fragrance as a hedonic product and bar soap as a utilitarian product based on past studies. Both perfume and bar soap fall under one product category which is personal care. This way of selection can eliminate the effects on personality perceptions arising from different product categories (Lim \& Ang, 2008).

\section{Data Collection}

Data for this research was collected from Amazon.com, which is a well-known online shopping portal. Amazon offers a widely accepted customer review system for online users to share their opinions and experiences on products. The customer review system includes detailed comments and an overall evaluation indicated by a five-star scale of user rating. Customer reviews from Amazon were collected in September 2016. Reviews were collected at a time when amazon used to provide customer helpfulness voting with the number of helpfulness votes for each review. In recent times, Amazon just provides the number of helpfulness votes, however, not the total number of votes for each review. Current information about helpfulness voting does not give a clear picture of the percentage of helpfulness. Hence, we decided to use the old data. Considering customer perspective, we believe 
the earlier helpfulness calculative mechanism provided by Amazon was more comprehensive and could have given a better understanding of the helpfulness than the present system.

As described above, this study chooses one hedonic product, perfume, and one utilitarian product, bar soap, as research subjects. For each of the products, this study analyzes all of the posted reviews on the Amazon website as of September 16, 2016. Following data were collected from each of the product reviews:

1. The total number of readers who voted in response to the question, "Was this review helpful to you (yes/no)?"

2. The number of readers who voted that the review was helpful.

3. The number of sentences in each review.

4. Number of hedonic sentences and utilitarian sentence as well as neutral sentences in each review.

Neutral sentences are those sentences that are neither hedonic nor utilitarian. For this study, a bar soap product with one of the highest numbers of total reviews $(2,298)$ and a perfume product with a total review of 2,058 are selected. Then, reviews with no helpfulness voting were excluded from the analysis. Further, reviews with less than 3 helpfulness ratings were excluded, too. The assumption is that one or two helpfulness ratings may not be enough to reflect the true helpfulness of reviews. For example, if a review with only one helpfulness rating saying that the review was helpful, then the review helpfulness of the review is counted as $100 \%$. That is, reviews with a too-small number of helpfulness ratings can mislead the results. Simultaneously, however, we do not want to lose too much data by excluding reviews with very strict criteria. We thought that 3 is a reasonable cutoff. Although there exist studies like Sen and Lerman (2007), which have taken a minimum of 1 helpfulness rating for data analysis, this study is performed in a little bit more conservative fashion due to the aforementioned reason. Eventually, 232 reviews were qualified for this study; 110 reviews for the hedonic product (i.e., perfume) and 122 reviews for the utilitarian product (i.e., bar soap). Although the numbers of reviews with helpfulness scores were quite low compared with the total numbers of reviews, it is a general trend for all kind of online products in Amazon. Consumers tend to read reviews, however, not many readers vote for review helpfulness.

\section{Measurement of Variables}

The dependent variable in the research model in this study is review helpfulness. Hedonicity and utilitarianity of reviews are used as the independent or other words explanatory variables and product type (hedonic and utilitarian) is used as the moderating variable. The number of sentences in a review is included as a control variable because a customer review may consist of a single sentence or may consist of several long paragraphs. Hedonicity or utilitarianity of a review with a single sentence may have a different interpretation of a review than with a few long paragraphs.

Review helpfulness is represented by the percentage of customers who found the review is helpful. That is, review helpfulness can be acquired by dividing the number of customers who voted that the review was helpful (i.e., who said yes) by the total votes in response to the "Was this review helpful to you (yes/no)?" question.

Each customer review is measured in terms of two dimensions of review type; hedonicity and utilitarianity. The variable of hedonicity represents the hedonic level of a review whereas the variable of utilitarianity represents utilitarian level of a review. Hedonicity of a review is based on the percentage of hedonic sentences that appeared in the review. Similarly, utilitarianity of a review is based on the percentage of utilitarian sentences that appeared in the review. To decide the values of hedonicity and utilitarianity, first, the type of sentences is categorized. Sentences can be classified into hedonic, utilitarian, and neutral ones. If a sentence includes one or more hedonic words, it is considered a hedonic sentence. The same is true for a utilitarian sentence. Some sentence contains neither hedonic nor utilitarian words or may have both hedonic and utilitarian words at the same 


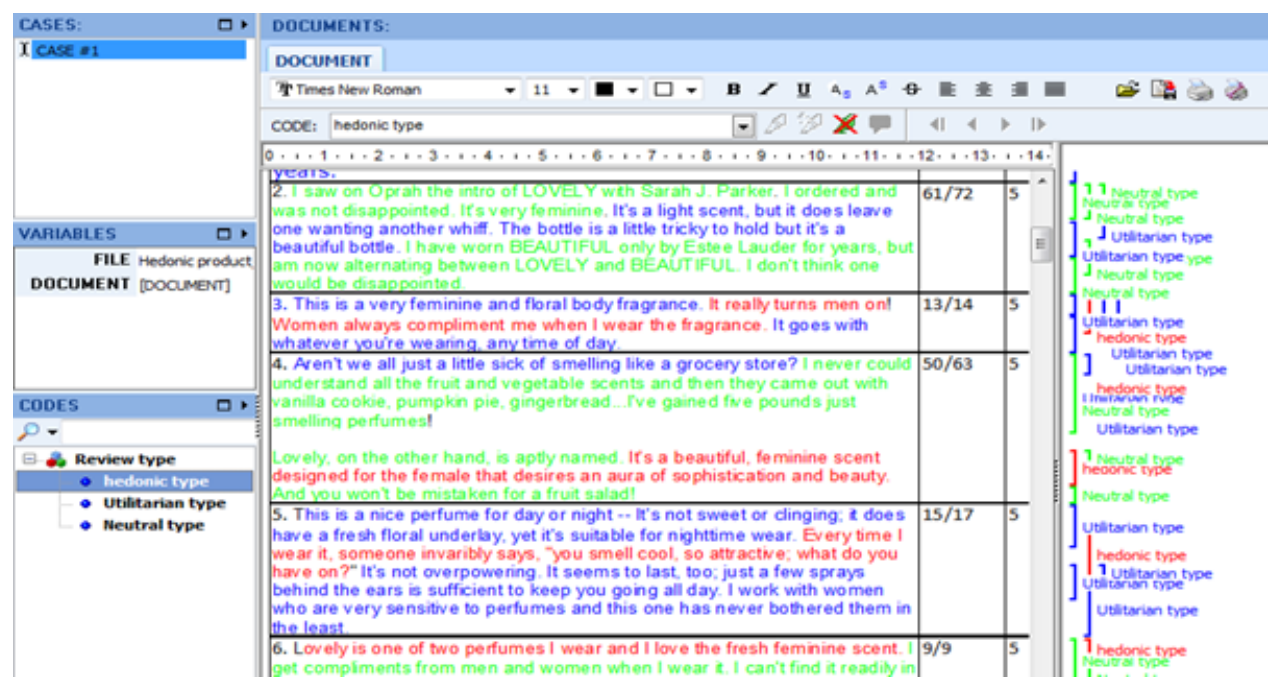

time. Such a sentence is considered a neutral sentence. Hedonicity of a review equals the number of hedonic sentences divided by the number of all sentences in the review. Utilitarianity of a review can be calculated similarly. For example, if a customer review consists of 10 sentences, where 6 of them are hedonic, 2 of them are utilitarian, and 2 of them are neutral. Then, the hedonicity of the review is $60 \%$ and the utilitarianity of the review is $20 \%$.

\section{Data Processing}

The review data that had been collected from Amazon.com was transferred into a database in a software package of text mining, namely QDA Miner v.4.1, which is used for qualitative data analysis for coding text and graphics, annotating, retrieving, and analyzing data and coded documents (QDA Miner User's Manual 2011). QDA Miner allows users to either type a full sentence or a list of words and it will retrieve text segments similar to their given example or words. The software has the functionality to pick similar sentences based on the sample sentences as well as keywords incorporated within the software. Users can simply check the sentences based on the highest similarity index and can accept or discard based on accuracy. The software consists of several tools, for instance, a text retrieval tool that can search for specific text patterns in documents. Coding retrieval is another tool that lists all text segments associated with some codes or with specific patterns of codes. Keyword retrieval is another important tool that can retrieve any document, paragraph, sentence, or coded segment containing a specific keyword or combination of keywords. This study uses the keyword retrieval feature to identify hedonic, utilitarian, and neutral sentences.

In QDA Miner, coding is the process of marking text segments as meaning units. The segments interpreted as connoting a similar meaning are marked with a label that is usually associated with a description of what the code means, common keywords for the text segments, and, perhaps, a general interpretation of them. In this study, QDA Miner coded each sentence as hedonic type, utilitarian type, and neutral type based upon a list of hedonic and utilitarian words called a data dictionary. Figure 2 illustrates a part of the result after running the QDA Miner to classify sentences. In the figure, each sentence is marked with different colors according to its types (i.e., hedonic, utilitarian, or neutral) and labeled with the relevant type name.

QDA Miner uses a data dictionary for classifying sentences into hedonic, utilitarian, and neutral types. Table 1 shows the data dictionary used for the classification. The data dictionary consists of two 
Table 1. Data dictionary for hedonic and utilitarian words

\begin{tabular}{|c|c|}
\hline Hedonic words & Synonyms \\
\hline Nice & $\begin{array}{l}\text { Awesome, Superb, Super, Cool, Great, Lovely, Fabulous, Dainty, Overnice, Prissy, } \\
\text { Squeamish, Courteous, Gracious }\end{array}$ \\
\hline Pleasant & Amazing, Astonishing, Astounding, Stunning, Surprising \\
\hline Happy & $\begin{array}{l}\text { Joyful, Jolly, Carefree, Cheery, Cheerful, Lighthearted, Beatific, Glad, Felicitous, } \\
\text { Excited, Happiness }\end{array}$ \\
\hline Curiosity & Oddity, Funny-Habit, Snoopiness \\
\hline Fantasy & $\begin{array}{l}\text { Fantasies, Phantasm, Fantasize, Fancy, Daydream, Fantasia, Utopia, Imagining, } \\
\text { Illusion, Delusion }\end{array}$ \\
\hline Joy & $\begin{array}{l}\text { Adorable, Amuse, Charmed, Cheering, Entertain, Flattering, Outstanding, Pleased, } \\
\text { Satisfied, Welcomed }\end{array}$ \\
\hline Fun & Playfulness, Amusement, Enjoyment, Entertainment, Relaxation, Jollity Great-Time \\
\hline Adventure & Excitement, Thrill, Exploit, Deed, Experience, Escapade \\
\hline Surprise & $\begin{array}{l}\text { Abrupt, Accidentally, Marvel, Prank, Suddenly, Trick, Unintentionally, Unique, } \\
\text { Unpredictable, Variable }\end{array}$ \\
\hline Festive & Cheerful, Jovial, Jolly, Merry, Joyful, Joyous, Jubilant \\
\hline Jealousy & Anxious, Attentive, Intolerant, Skeptical, Suspicious \\
\hline Fear & $\begin{array}{l}\text { Worry, Despair, Concern, Doubt, Panic, Scare, Anxiety, Jitters, Suspicion, Uneasy, } \\
\text { Dismay }\end{array}$ \\
\hline Excitement & Enthusiasm, Thrill, Delight, Joy, Arousal, Passion \\
\hline Utilitarian words & Synonymous \\
\hline Benefit & Profit, Beneficial, Gain, Aid, Prosperity, Asset, Assistance, Welfare \\
\hline Price & $\begin{array}{l}\text { Cost, Monetary Value, Toll, Bill, Discount, Demand, Payment, Rate, Tariff, } \\
\text { Expenditure, Expense, Fare, Fee, Pay, Valuation, Worth, Charge Wholesale }\end{array}$ \\
\hline Functional & Usable, Operable, Operational, Running, Working \\
\hline Useful & $\begin{array}{l}\text { Utile, Utilitarian, Helpful, Practical, Effective, Fruitful, Handy, Pragmatic, Proper, } \\
\text { Suitable, Appropriate, Advantageous }\end{array}$ \\
\hline Valuable & $\begin{array}{l}\text { Worth, Beneficial, Expensive, Helpful, Important, Costly, Treasured, Worthwhile, } \\
\text { Profitable, Prized, Valued, Precious, Wealth, Treasure, Durable }\end{array}$ \\
\hline Worthless & $\begin{array}{l}\text { Bogus, Cheap, Ineffective, Insignificant, Futile, Inconsequential, Meaningless, } \\
\text { Mediocre, Pointless, Unimportant, Unproductive, Despicable, Ugly, Vile, Slimy, } \\
\text { Unworthy, Wretched, Valueless }\end{array}$ \\
\hline
\end{tabular}

sets of words; one is a collection of hedonic words and their synonyms and the other is a collection of utilitarian words and their synonyms. The hedonic and utilitarian words were collected from past studies (Babin et al., 1994; Dhar \& Wertenbroch, 2000; Zhu \& Zhang, 2010) and were expanded to synonyms with the help of a well-known website http://wordnet.princeton.edu and dictionary.com. QDA Miner uses the words in the data dictionary to classify sentences. Once all sentences in a review are classified into hedonic, utilitarian, and neutral types, calculating hedonicity and utilitarianity of the review is straightforward by following the simple calculations described above.

Figure 3 illustrates the process of deciding hedonicity and utilitarianity of reviews by using QDA Miner as described so far. 
Figure 3. The decision process of review type levels

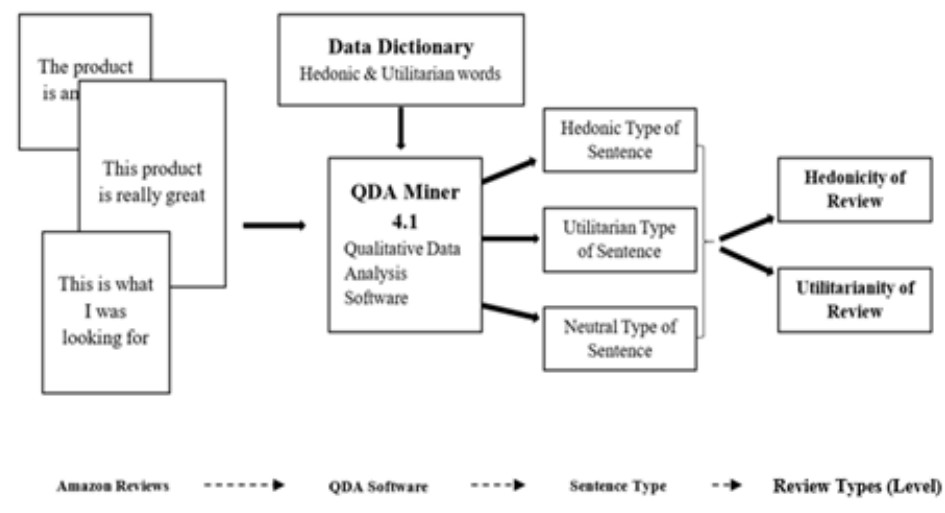

\section{Analysis Method}

A multi-group structural equation modeling approach is used to find if product type has a moderating effect on the relationship between hedonicity/utilitarianity of review and review helpfulness. A chisquare test is examined to check the moderating effect. For the utilitarian product, which is named Model A (Figure 4), all parameters are allowed to be unequal across the groups. The test result is compared to the result of the chi-square test done for hedonic products, named Model B (Figure 4), with the loadings constrained to be equal across the groups. In these models, no means or intercepts are estimated. The models with all parameters are freely estimated in the two groups.

\section{RESULTS}

In Figure 4, b1_1, b2_1, b3_1 and b1_2, b2_2, b3_2 are the names of the paths distinct for each group. To explain that a product type plays a significant moderating role we need to compare coefficients of b1_1 to b1_2, b2_1 to b2_2, and b3_1 to b3_2. Critical ratios for differences are calculated for the pairwise parameter comparison test (Table 2).

Although AMOS enables us to do all possible pairwise parameter comparisons, this study is interested in only a few of them which are highlighted in the matrix (Table 2). For this study path coefficients of b1, b2 and b3 are compared across models. The value of b1_1/b1_2 is equal to 1.982. It is a z-test for the difference between coefficients from 'Model A', to 'Model B' and for a two-tailed

Figure 4. Reviewing two models (Model A: Utilitarian product, Model B: Hedonic product)
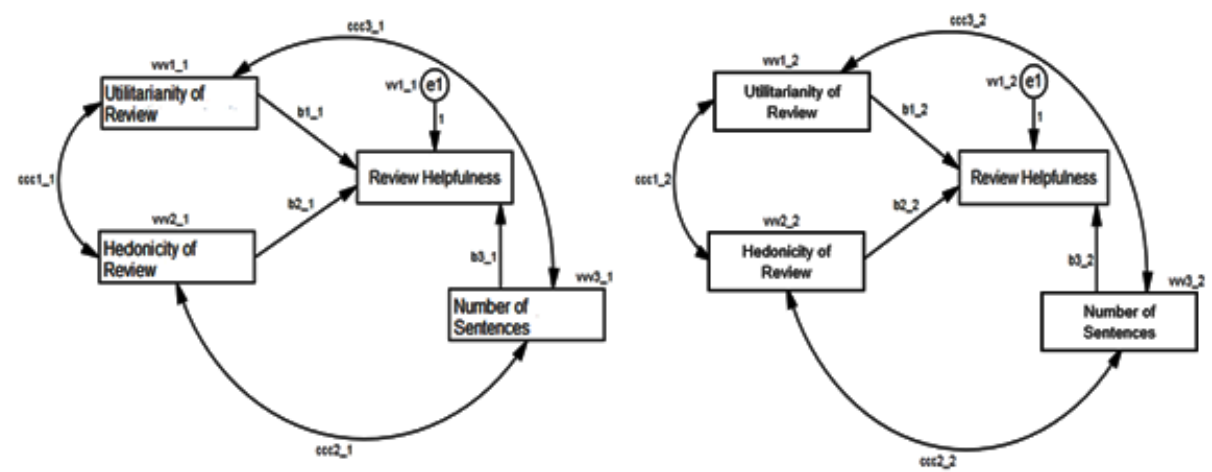
Table 2. Pairwise parameter comparisons (Default model)

\begin{tabular}{|c|c|c|c|c|c|c|c|c|c|c|c|c|c|c|c|c|}
\hline & b1_1 & b2_1 & ccc1_1 & ccc2_1 & b3_1 & ccc3_1 & vvv1_1 & vvv2_1 & $\mathrm{vvv3}{ }^{\prime} 1$ & vv1_1 & b1_2 & b2 $\_2$ & ccc1_2 & cec2 $\_2$ & $\begin{array}{l}\text { b3 } \\
\_2\end{array}$ & cec3_2 \\
\hline b1_1 & .000 & & & & & & & & & & & & & & & \\
\hline b2_1 & 2.564 & .000 & & & & & & & & & & & & & & \\
\hline ccc1_1 & -5.363 & -5.371 & .000 & & & & & & & & & & & & & \\
\hline ccc2_1 & -1.133 & -1.178 & 5.056 & .000 & & & & & & & & & & & & \\
\hline b3_1 & 2.131 & 1.257 & 5.383 & 1.244 & .000 & & & & & & & & & & & \\
\hline ccc3_1 & -.737 & -.764 & 4.855 & -.024 & -.806 & .000 & & & & & & & & & & \\
\hline vvv1_1 & 8.713 & 8.709 & 8.358 & 8.811 & 8.703 & 8.627 & .000 & & & & & & & & & \\
\hline vvv2_1 & 8.711 & 8.701 & 7.596 & 8.500 & 8.684 & 8.588 & -5.470 & .000 & & & & & & & & \\
\hline vvv3_1 & 8.687 & 8.585 & 6.089 & 4.474 & 8.393 & 3.046 & -8.345 & -7.727 & .000 & & & & & & & \\
\hline vv1_1 & 8.713 & 8.710 & 10.101 & 8.774 & 8.704 & 8.738 & .980 & 5.585 & 8.399 & .000 & & & & & & \\
\hline b1_2 & 1.982 & -.685 & 5.368 & 1.160 & -1.542 & .753 & -8.710 & -8.705 & -8.626 & -8.711 & .000 & & & & & \\
\hline b2_2 & -.712 & -2.306 & 5.360 & 1.118 & -2.297 & .728 & -8.714 & -8.715 & -8.716 & -8.714 & -2.157 & .000 & & & & \\
\hline ccc1_2 & -3.591 & -3.600 & 1.582 & -3.291 & -3.614 & -3.179 & -9.422 & -8.438 & -4.399 & -9.419 & -3.597 & -3.588 & .000 & & & \\
\hline cec2 22 & -5.321 & -5.374 & 4.486 & -2.551 & -5.446 & -1.801 & -9.087 & -9.574 & -8.867 & -9.035 & -5.353 & -5.304 & 2.775 & .000 & & \\
\hline b3_2 & 1.519 & 1.143 & 5.396 & 1.309 & .552 & .850 & -8.696 & -8.664 & -8.017 & -8.698 & 1.305 & 1.768 & 3.628 & 5.486 & .000 & \\
\hline ccc3_2 & 1.548 & 1.471 & 5.499 & 1.764 & 1.352 & 1.225 & -8.619 & -8.416 & -4.146 & -8.634 & 1.502 & 1.572 & 3.516 & 4.501 & 1.208 & .00 \\
\hline
\end{tabular}

test coefficient value expected to be greater than $|1.96|$ (the $\mathrm{z}$ value for $95 \%$ confidence interval). Path coefficient of our result is just slightly greater than $11.96 \mid$ (absolute value of 1.96) for the difference between paths to be statistically significantly different from one another in Model A. Though b1_1/ b3_1 has a value of 2.131 which is higher than 11.96 l however, this study does not have had an interest in these two paths. This study is purely interested in making cross-group comparisons. Looking at the $\mathrm{z}$-value for the cell b2_1/b2_2 is $(-2.306)$ which exceeds the critical value of |1.96I. Also, the value of .253 (the standardized regression weight for path b2_1) in Model A is statistically significantly different from the value of -.024 (the standardized regression weight for path b2_2) in Model B. In other words, the result shows enough evidence to suggest that the paths are not equal across the two models. Comparing b3_1/b3_2, the $\mathrm{z}$ score is .522 which does not exceed I1.96l. Further, both the value of .18 (the standardized regression weight for path b3_1) in Model A and the value of .17 (the standardized regression weight for path b3_2) in Model B are not statistically significant. Therefore, the 'number of sentences', which is the control variable of this study, does not affect the relationship between review type and review helpfulness.

Structural equation modeling is done with the help of AMOS 22 and research hypotheses are evaluated. Estimates and significance levels in the path diagram of the structural equation model are given in Figure 5. The results show an acceptable $t$ value (2.816) for hedonicity of review and online customer review helpfulness when the product type is utilitarian (Table 3). Whereas utilitarianity of review does not show an acceptable t value (0.907) with the review helpfulness when the product type is utilitarian (Table 3 ). The findings from path analysis for the structural model provide support for $\mathrm{H} 1(\mathrm{p}<0.01)$. The results in Table 3 explain that the utilitarian type of product has a significant positive moderation effect on hedonicity of review and review helpfulness. The critical ratio regarding for relationship between the control variable (number of sentences) and review helpfulness is $t$ value (2.340) and the control variable shows a significant relationship with review helpfulness at $\mathrm{p}<.05$ level. Therefore, it can be concluded that the number of sentences in a customer review affects the review helpfulness when the product type is utilitarian. 


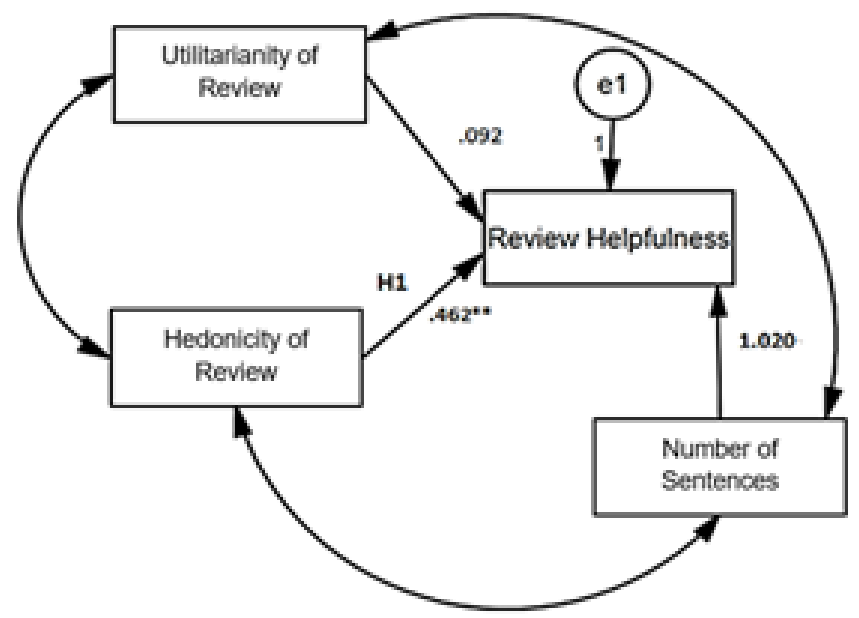

To test Hypothesis 2, we examine the critical ratio, in other words, $t$ value as it checked for Hypothesis 1, the results of regression weight (Figure 6) of the multi-group analysis show that utilitarianity of review has a significant $t$ value (2.247) at the level of $p(<.05)$ with the review helpfulness when the product type is hedonic. Whereas hedonicity of review does not show a significant $\mathrm{t}$ value (-.211) with review helpfulness (Table 4) when the product type is hedonic. The results explain that hedonic type of product has a significant positive moderation effect on the utilitarianity of review and review helpfulness. The critical ratio regarding the relationship between the control variable (number of sentences) and review helpfulness is the t value (1.618). However, the control variable does not show a significant relationship with review helpfulness at $p<.05$ level. Therefore, we may conclude that the number of sentences in a customer review does not an effect on the review helpfulness when the product type is hedonic.

\section{DISCUSSION}

The purpose of this study is to examine how product type (classified as hedonic and utilitarian) moderates the relationship between review type (measured as hedonicity and utilitarianity) and review helpfulness in an online context.

This study found that product type has a moderating effect on the relationship between review type and review helpfulness when the product type and review type have mismatched each other. Furthermore, this study found that the number of sentences, which might represent the length of review to some extent, affects review helpfulness when product type is utilitarian, while the number of sentences does not affect review helpfulness when the product type is hedonic. Earlier research

Table 3. Regression weights: (Utilitarian product - Default model)

\begin{tabular}{|l|l|l|l|l|l|}
\hline & \multicolumn{1}{|c|}{ Estimate } & \multicolumn{1}{|c|}{ S.E } & \multicolumn{1}{c|}{ C.R. } & \multicolumn{1}{c|}{ P } & \multicolumn{1}{c|}{ Label } \\
\hline Helpfulness <--- Utilitarianity & .092 & .101 & .907 & .364 & par_1 \\
\hline Helpfulness <--- Hedonicity & .462 & .164 & 2.816 & .005 & par_2 \\
\hline Helpfulness <--- No. of Sentences & 1.020 & .436 & 2.340 & .019 & par_5 \\
\hline
\end{tabular}

${ }^{*} p<.05,{ }^{* *} p<.01$ 


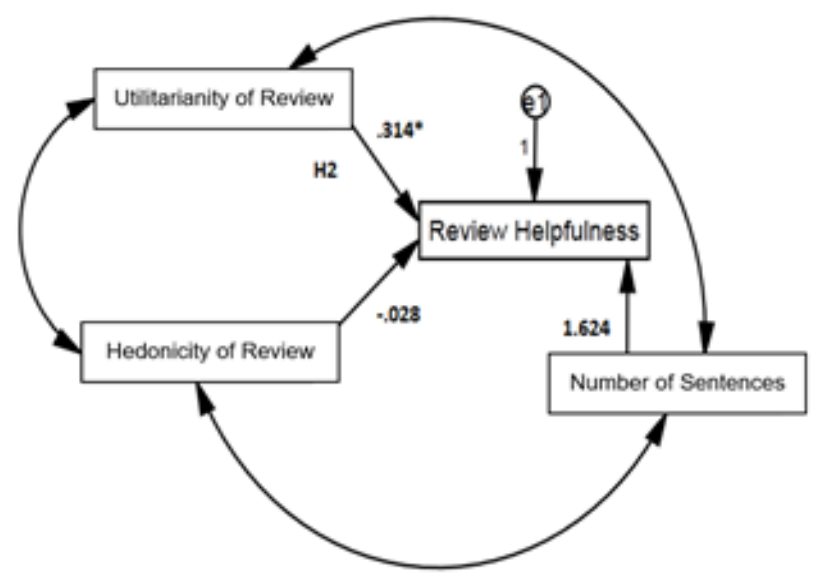

(Chevlier \& Mayzlin, 2006; Zhu \& Zhang, 2010) papers have mentioned the impact of online customer reviews and the dimension that impact their value, however, each prospective customer may have a different set of criteria and understanding to judge the value of the reviews. The findings of this paper propose a new perspective of the moderating role of product type on the relationships between review type or the number of sentences and review helpfulness.

Furthermore, hedonicity, which is the hedonic level of review enhances review helpfulness when the product type is utilitarian, and similarly utilitarianity, which is utilitarian level of review enhances review helpfulness when the product is hedonic type. In sum, the product type-review type mismatch tends to increase review helpfulness. The finding looks counter-intuitive. That is, the finding seems to be contrary to general intuition that utilitarian type of review is likely to show more helpfulness when the product is utilitarian based on functional benefits and the same is true for hedonic. Interestingly, however, the result of this study coincides with earlier studies that argued that ads promoting hedonic functionality over utilitarian are more preferable when the product is utilitarian (Lim \& Ang, 2008). As described earlier when proposing hypotheses, this kind of outcome may occur because incongruity between ads/review type and product type makes viewers/listeners/reviewers process the incongruent information more elaborately and make it more memorable (Mandler, 1982).

The results of this study also indicate that the number of sentences in a customer review affects the review helpfulness when the product type is not hedonic but utilitarian. The result may be interpreted as customers tend to seek more information when considering buying a utilitarian product than when considering to buy a hedonic product. The amount of information is likely to get bigger as the length

Table 4. Regression weights: (Hedonic product - Default model)

\begin{tabular}{|l|l|l|l|l|l|}
\hline & \multicolumn{1}{|c|}{ Estimate } & \multicolumn{1}{c|}{ S.E. } & C.R. & \multicolumn{1}{c|}{ P } & \multicolumn{1}{c|}{ Label } \\
\hline Helpfulness <--- Utilitarianity & .314 & .140 & 2.247 & .025 & par_7 \\
\hline Helpfulness <--- Hedonicity & -.028 & .135 & -.211 & .833 & par_8 \\
\hline Helpfulness <--- No. of Sentences & 1.624 & 1.003 & 1.618 & .106 & par_11 \\
\hline
\end{tabular}

${ }^{*} p<.05,{ }^{* *} p<.0$ 
of reviews increases. Further studies are necessary to confirm this finding. Outcomes of this study have potentially significant contributions for researchers and marketers.

\section{Theoretical Implications}

A hedonic type of review has high-arousal emotions, whereas a utilitarian type of review has high utility value. Researchers in the field of management recognized the important role of emotion in consumer decision making and research on emotion has been expanded dramatically (Loewenstein \& Lerner, 2003). Customer reviews affect the purchasing decision of other customers. Nevertheless, past studies on online review did not emphasize emotion, entertainment, fun, or hedonism but emphasized cognitive features of review content such as ease of reading, low rating, review trustworthiness, etc. In particular, earlier studies on online review helpfulness tended to address more on review rating, review depth, or positive or negative review characteristics. As far as we know, very few of them dealt with the hedonic and utilitarian characteristics of online reviews. Differentiating customer reviews in terms of hedonic and utilitarian types, this study reduced the gap in the literature. Especially, this study is worth as the first endeavor that explores the impacts of matching hedonic/utilitarian review type and hedonic/utilitarian product type on review helpfulness.

\section{Practical Implications}

Online marketers have been interesting in which factors of customer reviews affect purchasing decisions of other customers. Lots of studies have been done to support the need of marketers and found some factors which affect such decision making. For example, several studies found that comparatively negative reviews have the potential to influence the prospective customers' attitude and behaviors to a greater degree than positive reviews (Cao et al., 2011; Chevalier \& Mayzlin, 2006). Finding the relationship of review type and product type on review helpfulness, the present study contributes to fulfilling the need of marketers, too. The finding of this study recommends that marketers of utilitarian products need to emphasize hedonic benefits in their product descriptions and marketers of hedonic products need to specify utilitarian benefits in their product descriptions. The results of this study may help online marketers to create more valuable online reviews. For example, regarding utilitarian products, marketers may encourage the reviewer to write hedonic sentences by asking questions/ requests that induce hedonic type of answer. . Further, marketers may entice customers to write more sentences in review by employing appropriate reward schemes in case of utilitarian products.

\section{CONCLUSION}

This study introduces a new concept of review type classified in terms of hedonic-utilitarian perspective and proposes a way of measuring the degree of review type by identifying hedonic, utilitarian, and neutral sentences based on the existence of hedonic and/or utilitarian words in each sentence. The results of this study provide evidence that the hedonic property of review would be more helpful when the product type is utilitarian and similarly utilitarian property of review would be more helpful when the product type is hedonic. We believe that researchers and marketers will benefit greatly by considering the review type and the product type together from the perspective of hedonic and utilitarian to understand review helpfulness.

This study is not free from limitations. Although this study examined two different products (perfume and bar soap) of hedonic and utilitarian types within the same product category, adding several other products in both types could help to generalize the findings of this study. In addition, future research may explore the underlying mechanisms of why helpfulness is enhanced when product type is utilitarian and review type is hedonic and vice versa.

Furthermore, the research model of this study (Revisit the Figure 1) can also be extended by replacing existing variables with other possible variables that might affect review helpfulness, such as in-depth review or tourism products where a subjective or fun type of review matters more. Such 
a study may be particularly relevant since review helpfulness is a subjective judgment and could also be affected by the perceived credibility of the reviewer (Susan \& David, 2010). The present study did not consider an important category of factors that can affect review helpfulness, which are characteristics of review readers. Readers of reviews decide to review helpfulness and therefore, characteristics of the readers such as personality type are likely to affect the judgment of review helpfulness. Future studies that incorporate characteristics of readers into the model of this study may bring some interesting findings and new insights. 


\section{REFERENCES}

Adaval, R. (2001). Sometimes it just feels right: The differential weighting of affect-consistent and affectinconsistent product information. The Journal of Consumer Research, 28(1), 1-17.

Alba, J. W., \& Williams, E. F. (2013). Pleasure principles: A review of research on hedonic consumption. Journal of Consumer Psychology, 23(1), 2-18.

Archak, N., Ghose, A., \& Ipeirotis, P. G. (2011). Deriving the pricing power of product features by mining consumer reviews. Management Science, 57(8), 1485-1509.

Babin, B. J., Darden, W. R., \& Griffin, M. (1994). Work and/or fun: Measuring hedonic and utilitarian shopping value. The Journal of Consumer Research, 20(4), 644-656.

Bettiga, D., Bianchi, A. M., Lamberti, L., \& Noci, G. (2020). Consumers Emotional Responses to Functional and Hedonic Products: A Neuroscience Research. Frontiers in Psychology, 11. https://doi.org/10.3389/ fpsyg.2020.559779

Bhat, S., \& Reddy, S. K. (1998). Symbolic and functional positioning of brands. Journal of Consumer Marketing.

Bickart, B., \& Schindler, R. M. (2001). Internet forums as influential sources of consumer information. Journal of Interactive Marketing, 15(3), 31-40.

Cantallops, S. A., \& Salvi, F. (2014). New consumer behavior: A review of research on eWOM and hotels. International Journal of Hospitality Management, 36, 41-51. https://doi.org/10.1016/j.ijhm.2013.08.007

Cao, Q., Duan, W., \& Gan, Q. (2011). Exploring determinants of voting for the "helpfulness" of online user reviews: A text mining approach. Decision Support Systems, 50(2), 511-521.

Chen, Y., \& Xie, J. (2004). Online consumer review: A new... - Google Scholar. https://scholar.google. $\mathrm{com} / \mathrm{scholar} ? \mathrm{hl}=\mathrm{en} \& \mathrm{as} \_\mathrm{sdt}=0 \% 2 \mathrm{C} 5 \& \mathrm{q}=\mathrm{Chen} \% 2 \mathrm{C}+\mathrm{Y} . \% 2 \mathrm{C}+\mathrm{and}+\mathrm{Xie} \% 2 \mathrm{C}+\mathrm{J} .+\mathrm{Online}+\mathrm{consumer}+\mathrm{revi}$ ew $3 \mathrm{~A}+\mathrm{A}+$ new + element+of+marketing+communications+mix.+Working+Paper.+University+of+A rizona\% $2 \mathrm{C}+2004 \&$ btnG

Chen, Y., \& Xie, J. (2008). Online consumer review: Word-of-mouth as a new element of marketing communication mix. Management Science, 54(3), 477-491.

Chevalier, J. A., \& Mayzlin, D. (2006). The effect of word of mouth on sales: Online book reviews. JMR, Journal of Marketing Research, 43(3), 345-354.

Clemons, E. K., Gao, G. G., \& Hitt, L. M. (2006). When online reviews meet hyperdifferentiation: A study of the craft beer industry. Journal of Management Information Systems, 23(2), 149-171.

Dhar, R., \& Wertenbroch, K. (2000). Consumer choice between hedonic and utilitarian goods. JMR, Journal of Marketing Research, 37(1), 60-71.

Eisenhardt, K. M., \& Zbaracki, M. J. (1992). Strategic decision making. Strategic Management Journal, 13(2 S), 17-37. https://doi.org/10.1002/smj.4250130904

Flanagin, A. J., \& Metzger, M. J. (2013). Trusting expert-versus user-generated ratings online: The role of information volume, valence, and consumer characteristics. Computers in Human Behavior, 29(4), 1626-1634.

Freud, S. (1955). Beyond the pleasure principle. In The Standard Edition of the Complete Psychological Works of Sigmund Freud, Volume XVIII (1920-1922): Beyond the Pleasure Principle, Group Psychology and Other Works (pp. 1-64).

Gaertner, S. L., \& Dovidio, J. F. (1977). The subtlety of White racism, arousal, and helping behavior. Journal of Personality and Social Psychology, 35(10), 691.

Ghose, A., \& Ipeirotis, P. G. (2006). Designing ranking systems for consumer reviews: The impact of review subjectivity on product sales and review quality. Proceedings of the 16th Annual Workshop on Information Technology and Systems, 303-310.

Gomes, C. F. A., Brainerd, C. J., \& Stein, L. M. (2013). Effects of emotional valence and arousal on recollective and nonrecollective recall. Journal of Experimental Psychology. Learning, Memory, and Cognition, 39(3), 663. 
Guo, W., Liang, R.-Y., Wang, L., \& Peng, W. (2017). Exploring sustained participation in firm-hosted communities in China: The effects of social capital and active degree. Behaviour \& Information Technology, 36(3), $223-242$.

Ham, J., Lee, K., Kim, T., \& Koo, C. (2019). Subjective perception patterns of online reviews: A comparison of utilitarian and hedonic values. Information Processing \& Management, 56(4), 1439-1456. https://doi. org/10.1016/j.ipm.2019.03.011

Heilman, K. H. (1997). The neurobiology of emotional experience. The Neuropsychiatry of Limbic and Subcortical Disorders, 133-142.

Hlee, S., Lee, J., Yang, S.-B., \& Koo, C. (2019). The moderating effect of restaurant type on hedonic versus utilitarian review evaluations. International Journal of Hospitality Management, 77, 195-206.

Holbrook, M. B., \& Hirschman, E. C. (1982). The experiential aspects of consumption: Consumer fantasies, feelings, and fun. The Journal of Consumer Research, 9(2), 132-140.

Huang, A. H., Chen, K., Yen, D. C., \& Tran, T. P. (2015). A study of factors that contribute to online review helpfulness. Computers in Human Behavior, 48, 17-27.

Kensinger, E. A., \& Corkin, S. (2004). Two routes to emotional memory: Distinct neural processes for valence and arousal. Proceedings of the National Academy of Sciences of the United States of America, 101(9), 3310-3315.

Kim, S.-M., Pantel, P., Chklovski, T., \& Pennacchiotti, M. (2006). Automatically assessing review helpfulness. Proceedings of the 2006 Conference on Empirical Methods in Natural Language Processing, 423-430.

Kivetz, R., \& Simonson, I. (2002). Earning the right to indulge: Effort as a determinant of customer preferences toward frequency program rewards. JMR, Journal of Marketing Research, 39(2), 155-170.

Korfiatis, N., GarcíA-Bariocanal, E., \& SáNchez-Alonso, S. (2012). Evaluating content quality and helpfulness of online product reviews: The interplay of review helpfulness vs. review content. Electronic Commerce Research and Applications, 11(3), 205-217.

Kronrod, A., Grinstein, A., \& Wathieu, L. (2012). Enjoy! Hedonic consumption and compliance with assertive messages. The Journal of Consumer Research, 39(1), 51-61.

Leclerc, F., Schmitt, B. H., \& Dubé, L. (1994). Foreign branding and its effects on product perceptions and attitudes. JMR, Journal of Marketing Research, 31(2), 263-270.

Leggitt, J. S., \& Gibbs, R. W. (2000). Emotional reactions to verbal irony. Discourse Processes, 29(1), 1-24.

Li, J., Abbasi, A., Cheema, A., \& Abraham, L. B. (2020). Path to Purpose? How Online Customer Journeys Differ for Hedonic Versus Utilitarian Purchases. Journal of Marketing, 84(4), 127-146. doi:10.1177/0022242920911628

Lim, E. A. C., \& Ang, S. H. (2008). Hedonic vs. utilitarian consumption: A cross-cultural perspective based on cultural conditioning. Journal of Business Research, 61(3), 225-232.

Liu, F., Lim, E. T. K., Li, H., Tan, C.-W., \& Cyr, D. (2020). Disentangling utilitarian and hedonic consumption behavior in online shopping: An expectation disconfirmation perspective. Information \& Management, 57(3), 103199.

Loewenstein, G., \& Lerner, J. S. (2003). The role of affect in decision making. Handbook of Affective Science, $619(642), 3$.

López, I., \& Ruiz, S. (2011). Explaining website effectiveness: The hedonic-utilitarian dual mediation hypothesis. Electronic Commerce Research and Applications, 10(1), 49-58.

Luna, D., Peracchio, L. A., \& de Juan, M. D. (2003). The impact of language and congruity on persuasion in multicultural e-marketing. Journal of Consumer Psychology, 13(1-2), 41-50.

Mandler, G. (1982). The structure of value: Accounting for taste, 1982 in” Affect and cognition (M. S. Clark \& S. T. Fiske, Eds.). Erlbaum.

Mayzlin, D. (2006). Promotional chat on the Internet. Marketing Science, 25(2), 155-163.

Nelson, P. (1970). Information and consumer behavior. Journal of Political Economy, 78(2), 311-329. 
Park, D.-H., \& Kim, S. (2008). The effects of consumer knowledge on message processing of electronic wordof-mouth via online consumer reviews. Electronic Commerce Research and Applications, 7(4), 399-410.

Park, D.-H., Lee, J., \& Han, I. (2007). The effect of on-line consumer reviews on consumer purchasing intention: The moderating role of involvement. International Journal of Electronic Commerce, 11(4), 125-148.

Park, S., \& Nicolau, J. L. (2015). Asymmetric effects of online consumer reviews. Annals of Tourism Research, 50, 67-83. doi:10.1016/j.annals.2014.10.007

Rawlins, J., \& Metzger, S. (2014). The writer's way. Nelson Education.

Robey, D., \& Taggart, W. (1982). Human information processing in information and decision support systems. MIS Quarterly: Management Information Systems, 6(2), 61-73. doi:10.2307/249283

Sen, S., \& Lerman, D. (2007). Why are you telling me this? An examination into negative consumer reviews on the web. Journal of Interactive Marketing, 21(4), 76-94.

Strahilevitz, M., \& Myers, J. G. (1998). Donations to charity as purchase incentives: How well they work may depend on what you are trying to sell. The Journal of Consumer Research, 24(4), 434-446.

Susan, M. M., \& David, S. (2010). What makes a helpful online review? A study of customer reviews on amazon. com. Management Information Systems Quarterly, 34(1), 185-200.

Tedeshi, B. (1999). Consumer Products are Being Reviewed on More Web Site, Some Featuring Comments from Anyone with an Opinion. New York Times, Section C, 16.

Thompson, N. (2003). More companies pay heed to their'word of mouse'reputation. New York Times, 23, 4.

Voss, K. E., Spangenberg, E. R., \& Grohmann, B. (2003). Measuring the hedonic and utilitarian dimensions of consumer attitude. In Journal of Marketing Research (Vol. 40, Issue 3, pp. 310-320). https://doi.org/ doi:10.1509/ jmkr.40.3.310.19238

Wan, Y., Menon, S., \& Ramaprasad, A. (2007). A classification of product comparison agents. Communications of the ACM, 50(8), 65-71.

Wan, Y., \& Nakayama, M. (2014). The reliability of online review helpfulness. Journal of Electronic Commerce Research, 15(3), 179.

Wang, J.-J., Wang, L.-Y., \& Wang, M.-M. (2018). Understanding the effects of eWOM social ties on purchase intentions: A moderated mediation investigation. Electronic Commerce Research and Applications, 28, 54-62.

Wang, Y., Lu, X., \& Tan, Y. (2018). Impact of product attributes on customer satisfaction: An analysis of online reviews for washing machines. Electronic Commerce Research and Applications, 29, 1-11.

Ye, Q., Law, R., Gu, B., \& Chen, W. (2011). The influence of user-generated content on traveler behavior: An empirical investigation on the effects of e-word-of-mouth to hotel online bookings. Computers in Human Behavior, 27(2), 634-639.

Zhang, R., \& Tran, T. T. (2010). A novel approach for recommending ranked user-generated reviews. Canadian Conference on Artificial Intelligence, 324-327.

Zhu, F., \& Zhang, X. (2010). Impact of online consumer reviews on sales: The moderating role of product and consumer characteristics. Journal of Marketing, 74(2), 133-148. 
Maidul Islam is an assistant professor at the department of E-Trade at Keimyung University, South Korea. He holds a Ph.D. degree in Management Information Systems from Ajou University, South Korea, and a Master of Science from Visva-Bharati University, India, and also holds an MBA from Ming Chuan University, Taipei, Taiwan. He has published several top-tier international journal papers. He taught in several universities in South Korea, namely, Yonsei University, Kookmin University, Suwon University as well as Keimyung University. His research currently focuses on mobile commerce, cross-cultural study, Social networking, and customer review helpfulness on Amazon. Besides these, he is also a guest editor/reviewer of several SSCI/SCIE/Scopus indexed journals.

Mincheol Kang is a professor of e-Business Department in the School of Business, Ajou University, South Korea. He received a Ph.D. in engineering science from Rensselaer Polytechnic Institute, Troy, NY, USA. His current research area is IoT, augmented reality, mobile commerce, etc. He has published many papers in competitive journals, including IEEE Transactions on Systems, Man, and Cybernetics, Computers in Human Behavior, and the International Journal of Human-Computer Studies, among others. He is the corresponding author, email: mckang@ajou.ac.kr.

Tegegne Tesfaye Haile is an Assistant Professor of Global Business at The University of Suwon, South Korea. He received a PhD in Management Information Systems from Ajou University, South Korea. He has been teaching in higher education since 2007. Augmented reality advertising, internet of things, mobile commerce, and customer reviews are some of his current research areas. 